\title{
BMJ Open Association of tea consumption and the risk of gastric cancer in Japanese adults: the Japan Collaborative Cohort Study
}

\author{
Haytham Sheerah, ${ }^{1}$ Liu Keyang, ${ }^{1}$ Ehab Salah Eshak (1) , ${ }^{1,2}$ Renzhe Cui, ${ }^{1}$ \\ Kokoro Shirai, ${ }^{1}$ Isao Muraki, ${ }^{1}$ Hiroyasu Iso (D) , ${ }^{1}$ Akiko Tamakoshi ${ }^{3}$
}

To cite: Sheerah H, Keyang L, Eshak ES, et al. Association of tea consumption and the risk of gastric cancer in Japanese adults: the Japan Collaborative Cohort Study. BMJ Open 2020;10:e038243. doi:10.1136/ bmjopen-2020-038243

- Prepublication history and additional material for this paper are available online. To view these files, please visit the journal online (http://dx.doi. org/10.1136/bmjopen-2020 038243).

Received 09 March 2020

Revised 23 May 2020

Accepted 03 July 2020

A Check for updates

(c) Author(s) (or their employer(s)) 2020. Re-use permitted under CC BY-NC. No commercial re-use. See rights and permissions. Published by BMJ.

${ }^{1}$ Public Health, Department of Socia Medicine, Osaka University Graduate School of Medicine, Suita-shi, Osaka-fu, Japan

${ }^{2}$ Public Health and Preventive Medicine, Faculty of Medicine, Minia University, Minia, Minia,

Egypt

${ }^{3}$ Department of Public Health, Hokkaido University Graduate School of Medicine, Sapporo, Hokkaido, Japan

Correspondence to

Dr Hiroyasu Iso;

iso@pbhel.med.osaka-u.ac.jp

\section{ABSTRACT}

Objective To examine the possible relationship between tea consumption and risk of gastric cancer (GC) among Japanese men and women included in a large Japanese population-based study titled the Japan Collaborative Cohort (JACC) Study.

Design Prospective cohort study.

Setting A population-based cohort included subjects who were recruited from 24 areas of JACC Study, in which data regarding the incidence of cancer were available.

Participants 63848 participants (26 025 men and 37823 women), aged 40-79, were included in the analyses and underwent follow-up (median 13.3 years) prospectively in research on cancer incidence.

Primary and secondary outcome measures The primary outcome variable was the risk of $\mathrm{GC}$ according to the frequency intakes of total tea, green tea, black tea and oolong tea. The adjusted HRs for the risk of GC associated with tea consumption were calculated using the Cox proportional hazards model.

Results 1494 cases of GC were detected (960 men and 534 women) during the follow-up period. The multivariable-adjusted HRs for the risk of GC in the highest versus lowest quintiles of total tea intake were 1.05 (0.83-1.33); $p$ trend $=0.50$ in men, and $0.82(0.60-1.12)$; $p$ trend $=0.45$ in women. There was no association found between the consumption of green tea, black tea or oolong tea with the risk for GC in either gender.

Conclusions In this large community-based prospective cohort study, tea consumption was not associated with the risk of GC in either gender.

\section{INTRODUCTION}

Gastric cancer (GC) is one of the leading causes of cancer-related death worldwide and the most prevalent type of cancer in East Asia, ${ }^{1}$ including the Japanese population. ${ }^{2}$ The incidence of GC varies depending on the geographic location, time of year and socioeconomic status, suggesting that exposure to environmental causes and lifestyle factors are major contributors to the aetiology of GC. ${ }^{3}$

Tea is one of the most popular beverages worldwide. These beverages have the potential to reduce the risk of several types of cancer. ${ }^{4}$ Tea is made using the processed

\section{Strengths and limitations of this study}

The prospective study had a relatively long followup time of 13.4 years.

- The main limitation is the lack of data on Helicobacter pylori infection.

- There were very limited number of cardia gastric cancer (GC) cases to classify into cardia and noncardia GC

leaves, buds and stems of the Camellia sinensis plant. Based on processing, the final product may be black tea (100\% fermented), oolong tea $(50 \%$ fermented) or green tea $(0 \%$ fermented). ${ }^{5}$

Previous studies have shown that major polyphenols in tea (theaflavins and catechins) exert inhibitory effects on the proliferation of cancer cells, tumour growth, angiogenesis, metastasis and inflammation, as well as induce apoptosis against tumorigenesis. ${ }^{6} 7$ However, several large epidemiologic studies examining the association between the consumption of tea and the risk of GC have shown inconsistent results and drew conflicting conclusions; no associations, ${ }^{8-13}$ inverse associations ${ }^{14-16}$ or positive associations. ${ }^{1718}$ Moreover, there were some methodological shortages in the previous studies such as the short follow-up period and examining the impact of one type of tea only. ${ }^{13-19}$ Therefore, with the inconclusive evidence from the previous studies, the clarification is warranted on the associations of the intakes of different types of tea as well as the total tea intake with risk of GC in Japanese populations in whom GC is one of the most common cancers. We aimed in this study to investigate the associations between intakes of major tea types (green tea, black tea and oolong tea) and risk of GC among Japanese men and women. 


\section{METHODOLOGY}

\section{Study design}

The details of the Japan Collaborative Cohort (JACC) Study design and subjects have been described elsewhere. ${ }^{20}$ In brief, the study was initiated between 1988 and 1990 and involved a total of 110585 individuals (46 395 men and 64190 women) aged 40-79 years in 45 areas throughout Japan. Baseline information was collected through a self-administered questionnaire covering lifestyle choices and medical histories. Informed consent was obtained from each participant in 36 of the 45 study areas (written consent in 35 areas and oral consent in 1 area). In the remaining nine areas, group consent was obtained from each area leader.

\section{Inclusion and exclusion of the participants}

In the present study, subjects were recruited from 24 areas of the JACC Study, in which data regarding the incidence of cancer were available. Of the 65041 individuals, we excluded participants who have GC or medical history of cancer at baseline. The remaining 63848 subjects (26 025 men and 37823 women) were included in the analyses and underwent follow-up research on cancer incidence to examine the association between the consumption of tea and risk of GC. For the analysis of total tea, green tea, black tea and oolong tea, the final samples were 50716 , 59 568, 56796 and 52 964, respectively, after excluding subjects with missing consumption data for the beverage(s) under study.

\section{DIETARY ASSESSMENT}

The dietary section of the questionnaire included 40-item food frequency questionnare (FFQ) assessing the usual consumption of food and beverages in the previous 12 months. The frequency of tea consumption was initially assessed through the following questions: 'Do you drink Japanese (green) tea? Do you drink black tea? and Do you drink oolong tea?' The subjects were provided with five possible answers: every day (specify the number of cups), 3-4 cups per week, 1-2 cups per week, 1-2 cups per month and never. The validation of this dietary questionnaire has been described elsewhere, ${ }^{21}$ where the Spearman rank correlation coefficients between two frequencies (five categories) assessed with FFQ administered twice, 1 year apart were 0.74 for black tea, 0.62 for green tea and 0.61 for oolong tea, and the respective Spearman rank correlation coefficients between two frequencies (five categories) assessed with the FFQ and weighed dietary record for 12 days among 85 participants were 0.60 for black tea, 0.21 for green tea and 0.43 for oolong tea. We formed five categories for green tea, black tea and oolong tea: never, $<1$ cup per day, 1 cup per day, 2 cups per day and $\geq 3$ cups per day. For total tea intake, we changed the five frequencies of each type of tea consumed into a score; the frequency of never $=0$ score, $1-2$ times per month $=1.5 / 30=0.05$ score, $1-2$ times per week $=1.5 / 7=0.214$ score, $3-4$ times per week $=3.5 / 7=0.5$ score and the score for those reported an intake frequency 'every day' was the exact specified number of cups per day, then we summed the scores of the three types of tea. Afterward, we categorised the total summed score into five quintile groups (sex-specifically).

\section{GC ascertainment}

The follow-up survey for cancer incidence was available in 24 areas with a median follow-up period of 13.3 years. In most areas, the follow-up was completed to the end of 2009; however, it was stopped at the end of 1999 in four areas, at the end of 2003 in another four areas and at the end of 2008 in two areas. ${ }^{20}$ Data on cancer incidence such as date of diagnosis and primary site were collected through population-based cancer registers and in some study areas, the medical records of hospitals were also reviewed. Dates and causes of death were annually or biannually confirmed. The date of move out of cohort members from the study areas was also annually or biannually verified by the investigator in cooperation with key members of the local governmental office. Because some GC cases could not be reported at the time of diagnosis, but diagnosed at the time of death, we counted those cases as incident cases for calculation of incidence through systematic review of death certificate ( $\mathrm{n}=8$ cases). The incidence data were coded according to the 10th revision of the International Statistical Classification of Diseases (ICD-10) and Related Health Problems. Tumours with ICD-10 codes C16.0-C16.9 were classified as GC.

\section{STATISTICAL ANALYSIS}

The statistical analyses were based on the morbidity rates of GC during the follow-up period from 1988-1990 to the end of 2009. The person-years of follow-up were calculated from the date of completing the baseline questionnaire to the date of GC diagnosis, death, relocation or the end of the follow-up, whichever came first. Sex-specific baseline characteristics were calculated using age-adjusted 'mean (SD)' for continuous variables and proportions for categorical variables. Cox proportional hazards models were used to determine the sex-specific HRs and their 95\% CIs of the subsequent risk of GC for the different levels of consumption and types of tea. The multivariateadjusted models adjusted for age and residential area, educational level (education years $<16$ years or education years $\geq 16$ years), smoking status (never, ex-smoker, current), alcohol intake (never drink, ex-drinker, current), history of gastric and/or peptic ulcer (no, yes treated, yes under treatment, yes but not treated), family history of GC (yes or no) and consumption of Westernstyle breakfast (characterised by consumption of coffee, eggs, butter or margarine and bread) (yes or no). In addition, we adjusted for the intake of total energy and intake frequency of vegetables, fruits, meat, fish and salted foods (dried salted fish, miso soup and pickles), which were initially assessed through five possible answers: (do not eat, 1-2 times per month, 1-2 times per week, 3-4 times 
per week, almost every day). Miso soup intake was initially assessed through the following answer choices: (every day (how many cups), almost every day, several times a month and I don't drink much). We further adjusted mutually for green tea, black tea and oolong tea in a third model. We modelled the median daily intake of each category of tea consumption as a continuous variable to test for linear trends across the categories. All analyses were performed using the SAS statistical package, V.9.4 (SAS Institute). A $p$ value less than 0.05 denoted the presence of statistical significance.

\section{Patient and public involvement}

Patients or the public were not involved in the study.

\section{RESULTS}

During the follow-up period (median 13.3 years), a total of 1494 cases of GC were detected (960 men and 534 women). Within 674381 person-years of follow-up of 50716 with estimated total tea intake, there were 1183 incident cases of GC; within 780054 person-years of follow-up of 59568 subjects with non-missing green tea intake, there were 1422 incident cases of GC; within 744 069 person-years of follow-up of 56796 subjects with nonmissing black tea intake, there were 1307 incident cases of GC and within 702554 person-years of follow-up of 52 964 subjects with non-missing oolong tea intake, there were 1234 incident cases of GC.

\section{Total tea and GC}

Men and women in the highest quintiles of total tea were more educated, more likely to be smokers, more likely to have family history of GC, had higher intake of salt, less likely to consume alcohol and less likely to have a Western-style breakfast compared with those in the lowest quintile (table 1). Table 2 shows no association between the consumption of total tea and the risk of GC in either gender.

\section{Green tea and GC}

Men and women who consumed $\geq 3$ cups/day of green tea were older, more educated, less likely to have Westernstyle breakfast, had higher intake of salt (attributed to higher consumption of Japanese staple foods of high salt intake such as miso soup, salted dry fish, pickles, etc) and drank less alcohol compared with those who did not consume green tea. The prevalence of smoking in men who consumed the higher intake of green tea was higher than in male non-green tea consumers, while the opposite was found in women (online supplementary table 1-1). table 2 shows no association between the consumption of green tea and the risk of GC in either gender.

\section{BLACK TEA AND GC}

Men and women who consumed $\geq 3$ cups/day of black tea were more educated, more likely to be smokers, more likely to have a Western-style breakfast, had less intake of salt (attributed to low consumption Japanese staple salty foods and more Westernised diet), less likely to have a family history of GC and drank less alcohol compared with those who did not consume black tea (online supplemental tables 1-2). table 2 shows no association between the consumption of black tea and the risk of GC in either gender.

\section{Oolong tea and GC}

Men and women who consumed $\geq 3$ cups/day of oolong tea were younger, more educated, drank more alcohol and more likely to have a Western-style breakfast, and had less intake of salt compared with those who did not consume oolong tea. However, contrary to that in men, women who consumed higher intake of oolong tea were more likely to be smokers than non-oolong tea consumers (online supplemental tables 1-3). table 2 shows no association between the consumption of oolong tea and the risk of GC in either gender.

\section{DISCUSSION}

In this large prospective Japanese cohort study, we found no association between the consumption of the total tea, green tea, black tea or oolong tea with the risk of GC in either gender.

A systematic review and meta-analysis of five cohort and eight case-control studies concluded an overall null association between green tea intake and risk of GC in cohort studies; pooled relative risk (RR) (95\% CI) was 1.05 (0.90, $\left.1.21, \mathrm{I}^{2}=20.3 \%\right)$, and suggested lower risk in case-control studies; pooled OR $(95 \% \mathrm{CI})$ was $0.84\left(0.74,0.95, \mathrm{I}^{2}=48.3\right.$ $\%)^{22}$

Consistent with findings of the previous cohort studies, ${ }^{9-13}$ the present Japanese cohort study did not reveal any associations between the consumption of green tea and the risk of GC. In another Japanese cohort study of 38540 men and women, the intake of $\geq 5$ cups/day green tea in reference to intake of $0-1 \mathrm{cup} /$ day was associated with a $\mathrm{RR}$ of $\mathrm{GC}=0.98(0.89-1.10$; $\mathrm{p}$ trend $=0.62){ }^{9}$ Furthermore, a national Japanese cohort study, titled the Japanese Public Health Center-based Prospective Study, showed no association between green tea consumption and the risk of either cardia or non-cardia GC. The multivariable-adjusted RR (95\% CI) in individuals consuming green tea $\geq 5$ cups/day versus consuming $<1$ cup was $0.67(0.43-1.04)$ in men and $0.67(0.43-1.04)$ in women. ${ }^{11}$ Although, in a Chinese prospective study on 0.5 million Chinese adults, an increased risk of GC with $\geq 4 \mathrm{~g}$ / day intake of green tea leaves versus less than weekly tea consumption was observed; RR (95\% CI) was 1.27 (1.101.46; $\mathrm{p} \leq 0.001)$, in-depth analysis limited the increased risk to male non-smokers non-excessive alcohol drinkers and the authors stressed on the possibility of chance findings because of the limited GC cases in that specific group. ${ }^{18}$ Consumption of black tea is not popular in Japan compared with that of green tea ${ }^{15}$ while black tea is the most commonly consumed tea in Western countries. ${ }^{16}$ 
Table 1 Sex-specific mean and SD and proportions of risk characteristics for GC according to total tea intake

\begin{tabular}{|c|c|c|c|c|c|c|}
\hline $\begin{array}{l}\text { Total tea } \\
\text { Range (median) of average } \\
\text { frequency, times/day }\end{array}$ & $\begin{array}{l}\text { Q1 } \\
\text { Never }\end{array}$ & $\begin{array}{l}\text { Q2 } \\
<1 \text { cup/day }\end{array}$ & $\begin{array}{l}\text { Q3 } \\
1 \text { cup/day }\end{array}$ & $\begin{array}{l}\text { Q4 } \\
2 \text { cups/day }\end{array}$ & $\begin{array}{l}\text { Q5 } \\
\geq 3 \text { cups/day }\end{array}$ & P trend ${ }^{*}$ \\
\hline \multicolumn{7}{|l|}{ Men } \\
\hline Age, years (SD) & $56.8(10.5)$ & $55.7(10.3)$ & $56.7(10.5)$ & $57.7(10.0)$ & $57.8(9.6)$ & $<0.0001$ \\
\hline Education $\geq 16$ years, $\%$ & 49.5 & 58.2 & 66.3 & 61.9 & 63.7 & $<0.0001$ \\
\hline Alcohol intake, g/day (SD) & $33.9(22.7)$ & $33.2(22.0)$ & $32.4(21.5)$ & $32.8(21.1)$ & $32.1(21.8)$ & 0.0020 \\
\hline $\begin{array}{l}\text { Body Mass Index (BMI) kg/ } \\
\mathrm{m}^{2}(\mathrm{SD})\end{array}$ & $22.7(2.8)$ & $22.9(2.8)$ & $22.6(2.7)$ & $22.6(2.7)$ & $22.8(2.8)$ & 0.4716 \\
\hline Family history of GC, \% & 12.0 & 12.0 & 11.8 & 13.1 & 14.7 & 0.1988 \\
\hline Western style of breakfast, \% & 14.0 & 17.8 & 19.5 & 11.8 & 11.2 & $<0.0001$ \\
\hline Meat intake g/day (SD) & $26.8(19.9)$ & $28.3(19.1)$ & $28.1(19.3)$ & $28.9(19.9)$ & $29.7(19.8)$ & $<0.0001$ \\
\hline Fish intake g/day (SD) & $45.2(27.3)$ & $45.4(26.9)$ & $45.3(26.1)$ & $47.8(26.7)$ & $50.4(27.1)$ & $<0.0001$ \\
\hline Energy intake, kcal/day & $1650.9(487.2)$ & $1665.0(469.9)$ & $1637.3(437.0)$ & $1718.7(447.4)$ & $1806.2(462.5)$ & $<0.0001$ \\
\hline \multicolumn{7}{|l|}{ Woman } \\
\hline No. of patients at risk & 6628 & 4307 & 6871 & 6248 & 5877 & \\
\hline Age, years (SD) & $57.5(10.3)$ & $55.9(10.1)$ & $57.3(10.2)$ & $58.1(9.8)$ & $57.5(9.7)$ & $<0.0001$ \\
\hline Education $\geq 16$ years, $\%$ & 46.6 & 53.6 & 63.4 & 59.3 & 64.6 & $<0.0001$ \\
\hline Current smoking, $\%$ & 5.1 & 5.8 & 4.2 & 4.6 & 6.1 & $<0.0001$ \\
\hline Alcohol intake, g/day (SD) & $10.4(13.5)$ & $9.4(11.6)$ & $9.2(12.9)$ & 9.5 (11.9) & $9.2(12.7)$ & 0.0648 \\
\hline Meat intake g/day (SD) & $27.5(19.6)$ & $30.3(20.1)$ & $29.8(20.2)$ & $30.4(20.8)$ & $31.0(20.7)$ & $<0.0001$ \\
\hline Fish intake g/day (SD) & $45.1(26.5)$ & $46.6(26.4)$ & $46.3(25.6)$ & $48.5(26.4)$ & 50.7 (26.9) & $<0.0001$ \\
\hline Energy intake, kcal/day & 1372.8 (353.6) & $1383.6(349.6)$ & $1392.1(342.8)$ & $1440.1(346.4)$ & $1463.7(338.4)$ & $<0.0001$ \\
\hline
\end{tabular}

*Age-adjusted $p$ trend was calculated by linear regression for continuous variables and logistic regression for categorical variables.

GC, gastric cancer.

Several studies examining the association between the consumption of black tea and the risk of GC have shown no association. ${ }^{81315}$ We also found that there was no association between the risk of GC and the consumption of black tea. However, in the European Prospective Investigation into Cancer and Nutrition (EPIC) Study of 477312 men and women, the multivariable-adjusted HR $(95 \%$ CI) for GC in the highest versus the lowest quartiles of tea intake was $0.81(0.59-1.09$, $\mathrm{p}$ trend $=0.13)$. The association was evident for women $(\mathrm{HR}=0.59 ; 95 \% \mathrm{CI}, 0.36$ to 0.97 , $\mathrm{p}$ trend $=0.02$ ) but not for men (HR=1.01; 95\% CI, 0.68 to $1.48, \mathrm{p}$ trend $=0.93) .{ }^{16}$ The exact mechanisms responsible for the sex difference (ie, reduced risk in women but not in men) were not explained. However, a report from the EPIC Study indicated that the protective effects of total dietary flavonoids (mainly obtained from tea) were inversely associated with the risk of GC in women only. ${ }^{23}$ In a 14-year follow-up study of 3158 Japanese men and women living in Hokkaido, there were no associations between black tea consumption and the risk of GC in men, whereas the HR (95\% CI) of GC among women who consumed black tea for several times per week or everyday was 3.8 (1.1-13.6) compared with women who never consumed black or consumed it several times per year or several times per month. However, after adjusting for the intakes of salty confectionary and carbonated drink/juice, the association disappeared; HR $(95 \%$ $\mathrm{CI})=3.0(0.8-11.2) .{ }^{17}$

The present study did not show any association between oolong tea intake and the risk of GC. Evidence regarding 


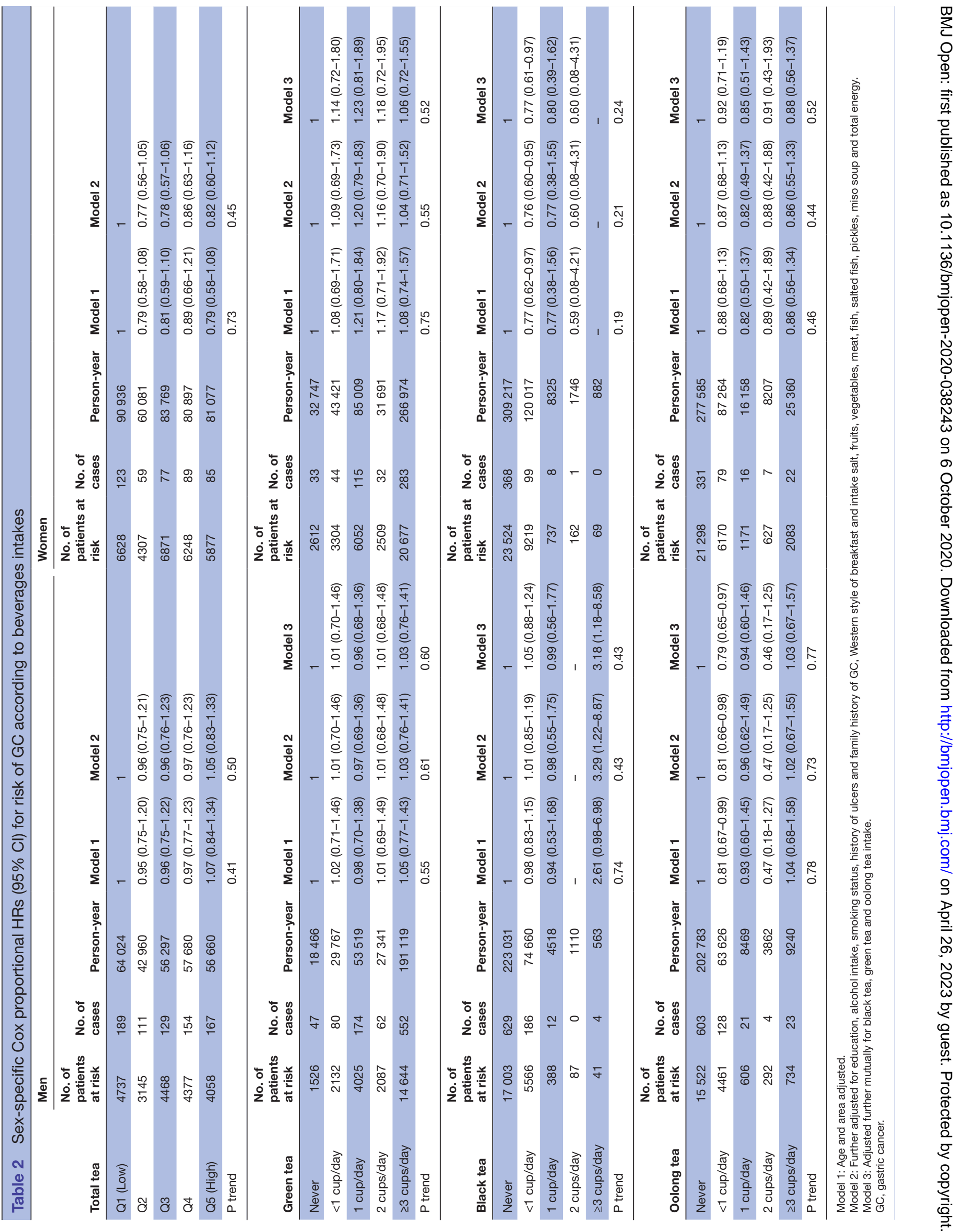


the association between oolong tea intake and GC risk is currently limited. Oolong tea was shown to have an inhibitory effect on carcinogenesis in the human stomach cancer cells ${ }^{24}$ and that high molecular weight fractions of oolong tea induced apoptosis in human GC cell line MKN-45 cells. ${ }^{25} \mathrm{f}$

\section{Strengths of the study}

This prospective study had a relatively long follow-up time of 13.4 years for a large cohort. It also estimated the intakes of tea by a validated food frequency questionnaire and had a good-quality cancer registry system.

\section{Limitations of the study}

The main limitation of the present study related to residual confounding by lack of data regarding an important risk factor of GC, that is, Helicobacter pylori infection. However, in a previous nested case-control study within the JACC Study of 157 incident GC cases and 285 controls for whom the $H$. pylori infection data were available, no association between green tea intake and the risk of GC was confirmed after adjusting for $H$. pylori infection; the multivariableadjusted RR (95\% CI) was $1.2(0.6-2.5)$ for individuals consuming green tea $\geq 10 \mathrm{cups} /$ day versus consuming $<1$ cup. ${ }^{26}$ A previous study showed that the prevalence of $H$. pylori infection among seven geographic areas in Japan ranged from $29.4 \%$ in Hokkaido prefecture to $54.5 \%$ in Yamagata Prefecture. ${ }^{27}$ In general, the prevalence of $H$. pylori related diseases has decreased in Japan and is likely to continue to decrease due to the improvement of sanitary conditions and the use of antibiotics. ${ }^{28}$ Second, the lack of repeated measurements for the consumption of beverages, since these variables may have changed during the long follow-up period. In addition, we were unable to determine whether the consumed tea was decaffeinated or not; however, decaffeinated beverages were not common in Japan. ${ }^{29}$ Lastly, we have a limited number of cardia GC (total 70 case) with a very few cases in the reference group of green tea (three cases) and no cases were found in the highest groups of black tea consumptions (zero cases in either 2 cups black tea/day or $\geq 3$ cups black tea/day); therefore, we did not have the statistical power to conduct the separate analysis by GC site. However, in a sensitivity analysis excluding cardia GC cases, the null association was still evident for tea consumption with risk of non-cardia GC.

\section{CONCLUSION}

In conclusion, in this large community-based prospective cohort study, the intakes of neither total tea nor tea types were associated with the risk of GC in either gender. Although tea intake was recommended for the prevention of other chronic diseases, such as diabetes, ${ }^{29}$ cardiovascular diseases ${ }^{30}$ and other cancers, ${ }^{40}$ the clinical implication and recommendation of high consumption of green and or black tea for the prevention of GC should be revised in light of null and inconsistent findings of the current and previous cohort studies.

Acknowledgements The authors would like to thank all the staff involved in this study for their valuable help in conducting baseline surveys and follow-up.

Contributors $\mathrm{HI}$ and AT designed this research; HS conducted the analyses and prepared the manuscript; HI, LK, RC, ESE, KS, IM and AT critically reviewed the manuscript and $\mathrm{HI}$ assumed primary responsibility for the final content. The manuscript is approved by all authors for publication.

Funding This study has been supported by Grants-in-Aid for Scientific Research from the Ministry of Education, Culture, Sports, Science and Technology of Japan (MEXT) (MonbuKagaku-sho); Grants-in-Aid for Scientific Research on Priority Areas of Cancer; and Grants-in-Aid for Scientific Research on Priority Areas of Cancer Epidemiology from MEXT (Nos. 61010076, 62010074, 63010074, 1010068, 2151065, 3151064, 4151063, 5151069, 6279102, 11181101, 17015022, 18014011, 20014026, 20390156, 26293138), and JSPS KAKENHI No.16H06277. This research was also supported by Grant-in-Aid from the Ministry of Health, Labour and Welfare, Health and Labor Sciences research grants, Japan (Comprehensive Research on Cardiovascular Disease and Life-Style Related Diseases: H20-Junkankitou [Seishuu]-Ippan-013; H23-Junkankitou [Seishuu]-Ippan-005); an Intramural Research Fund (22-4-5) for Cardiovascular Diseases of National Cerebral and Cardiovascular Center; Comprehensive Research on Cardiovascular Diseases and Life-Style Related Diseases (H26-Junkankitou [Seisaku]-Ippan-001) and H29-Junkankitou [Seishuu]-Ippan-003 and 20FA1002. Competing interests None declared.

Patient and public involvement Patients and/or the public were not involved in the design, or conduct, or reporting, or dissemination plans of this research.

Patient consent for publication Not required.

Ethics approval This study was approved by the ethics committees of Hokkaido University, Hokkaido, Japan, and Osaka University, Osaka, Japan. number/ID 14285-6.

Provenance and peer review Not commissioned; externally peer reviewed.

Data availability statement The raw/processed data required to reproduce these findings cannot be shared at this time as the data also forms part of an ongoing study.

Open access This is an open access article distributed in accordance with the Creative Commons Attribution Non Commercial (CC BY-NC 4.0) license, which permits others to distribute, remix, adapt, build upon this work non-commercially, and license their derivative works on different terms, provided the original work is properly cited, appropriate credit is given, any changes made indicated, and the use is non-commercial. See: http://creativecommons.org/licenses/by-nc/4.0/.

\section{ORCID iDs}

Ehab Salah Eshak http://orcid.org/0000-0002-3564-1938

Hiroyasu Iso http://orcid.org/0000-0002-9241-7289

\section{REFERENCES}

1 Rawla P, Barsouk A. Epidemiology of gastric cancer: global trends, risk factors and prevention. Prz Gastroenterol 2019;14:26-38.

2 Truong Minh P, Fujino Y, Yoshimura T, et al. Mortality and incidence rates of stomach cancer in the JACC study. J Epidemiol 2005;15 Suppl 2:S89-97.

3 Sitarz R, Skierucha M, Mielko J, et al. Gastric cancer: epidemiology, prevention, classification, and treatment. Cancer Manag Res 2018;10:239-48.

4 Zhang Y-F, Xu Q, Lu J, et al. Tea consumption and the incidence of cancer: a systematic review and meta-analysis of prospective observational studies. Eur J Cancer Prev 2015;24:353-62.

5 Cabrera C, Giménez R, López MC. Determination of tea components with antioxidant activity. J Agric Food Chem 2003;51:4427-35.

6 Sasazuki S, Inoue M, Miura T, et al. Plasma tea polyphenols and gastric cancer risk: a case-control study nested in a large populationbased prospective study in Japan. Cancer Epidemiology Biomarkers \& Prevention 2008;17:343-51.

7 Lambert JD. Does tea prevent cancer? Evidence from laboratory and human intervention studies. Am J Clin Nutr 2013;98:1667S-75.

8 Inoue M, Tajima K, Hirose K, et al. Life-style and subsite of gastric cancer--joint effect of smoking and drinking habits. Int $J$ Cancer 1994;56:494-9. 
9 Nagano J, Kono S, Preston DL, et al. A prospective study of green tea consumption and cancer incidence, Hiroshima and Nagasaki (Japan). Cancer Causes Control 2001;12:501-8.

10 Tsubono $\mathrm{Y}$, Nishino $\mathrm{Y}$, Komatsu S, et al. Green tea and the risk of gastric cancer in Japan. N Engl J Med 2001;344:632-6.

11 Sasazuki S, Inoue M, Hanaoka T, et al. Green tea consumption and subsequent risk of gastric cancer by subsite: the JPHC study. Cancer Causes Control 2004;15:483-91.

12 Nechuta S, Shu X-O, Li H-L, et al. Prospective cohort study of tea consumption and risk of digestive system cancers: results from the Shanghai women's health study. Am J Clin Nutr 2012;96:1056-63.

13 Hashibe M, Galeone C, Buys SS, et al. Coffee, tea, caffeine intake, and the risk of cancer in the PLCO cohort. Br J Cancer 2015;113:809-16.

14 Yu GP, Hsieh CC, Wang LY, et al. Green-tea consumption and risk of stomach cancer: a population-based case-control study in Shanghai, China. Cancer Causes Control 1995;6:532-8.

15 Inoue M, Tajima K, Hirose K, et al. Tea and coffee consumption and the risk of digestive tract cancers: data from a comparative case-referent study in Japan. Cancer Causes Control 1998:9:209-16.

16 Sanikini H, Dik VK, Siersema PD, et al. Total, caffeinated and decaffeinated coffee and tea intake and gastric cancer risk: results from the EPIC cohort study. Int $J$ Cancer 2015; 136:E720-30.

17 Khan MMH, Goto R, Kobayashi K, et al. Dietary habits and cancer mortality among middle aged and older Japanese living in Hokkaido, Japan by cancer site and sex. Asian Pac J Cancer Prev 2004:5:58-65.

$18 \mathrm{Li} \mathrm{X,} \mathrm{Yu} \mathrm{C,} \mathrm{Guo} \mathrm{Y,} \mathrm{et} \mathrm{al.} \mathrm{Association} \mathrm{between} \mathrm{tea} \mathrm{consumption} \mathrm{and}$ risk of cancer: a prospective cohort study of 0.5 million Chinese adults. Eur J Epidemiol 2019;34:753-63.

19 Tsugane S, Sasazuki S. Diet and the risk of gastric cancer: review of epidemiological evidence. Gastric Cancer 2007;10:75-83.
20 Tamakoshi A, Ozasa K, Fujino Y, et al. Cohort profile of the Japan collaborative cohort study at final follow-up. J Epidemiol 2013;23:227-32.

21 Date C, Fukui M, Yamamoto A, et al. Reproducibility and validity of a self-administered food frequency questionnaire used in the JACC study. J Epidemiol 2005;15:S9-23.

22 Huang Y, Chen $\mathrm{H}$, Zhou L, et al. Association between green tea intake and risk of gastric cancer: a systematic review and doseresponse meta-analysis of observational studies. Public Health Nutr 2017;20:3183-92.

23 Zamora-Ros R, Agudo A, Luján-Barroso L, et al. Dietary flavonoid and lignan intake and gastric adenocarcinoma risk in the European prospective investigation into cancer and nutrition (EPIC) study. Am J Clin Nutr 2012;96:1398-408.

24 Hibasami H, Jin ZX, Hasegawa M, et al. Oolong tea polyphenol extract induces apoptosis in human stomach cancer cells. Anticancer Res 2000;20:4403-6.

25 Hayakawa S, Kimura T, Saeki K, et al. Apoptosis-Inducing activity of high molecular weight fractions of tea extracts. Biosci Biotechnol Biochem 2001;65:459-62.

26 Hoshiyama Y, Kawaguchi T, Miura Y, et al. A nested case-control study of stomach cancer in relation to green tea consumption in Japan. Br J Cancer 2004;90:135-8.

27 Ueda J, Gosho M, Inui Y, et al. Prevalence of Helicobacter pylori infection by birth year and geographic area in Japan. Helicobacter 2014:19:105-10.

28 Inoue M. Changing epidemiology of Helicobacter pylori in Japan. Gastric Cancer 2017;20:3-7.

29 Iso H, Date C, Wakai K, et al. The relationship between green tea and total caffeine intake and risk for self-reported type 2 diabetes among Japanese adults. Ann Intern Med 2006;144:554-62.

30 Tang J, Zheng J-S, Fang L, et al. Tea consumption and mortality of all cancers, CVD and all causes: a meta-analysis of eighteen prospective cohort studies. Br J Nutr 2015;114:673-83. 